\title{
Check Up on Anaesthesia for Caesarean Section in a Medical Center with Surgical Antenna in Bobo-Dioulasso, Burkina Faso
}

\author{
Barro S. D. ${ }^{1,3, \text {, }}$, Somé D. ${ }^{2,3}$, Traoré I. A. ${ }^{1,3}$, Guibla I. ${ }^{1}$, Meda Z. C. ${ }^{3,4}$, Ouattara S., 3 , Dao B. ${ }^{3,5}$, \\ Bayala B. $^{6}$

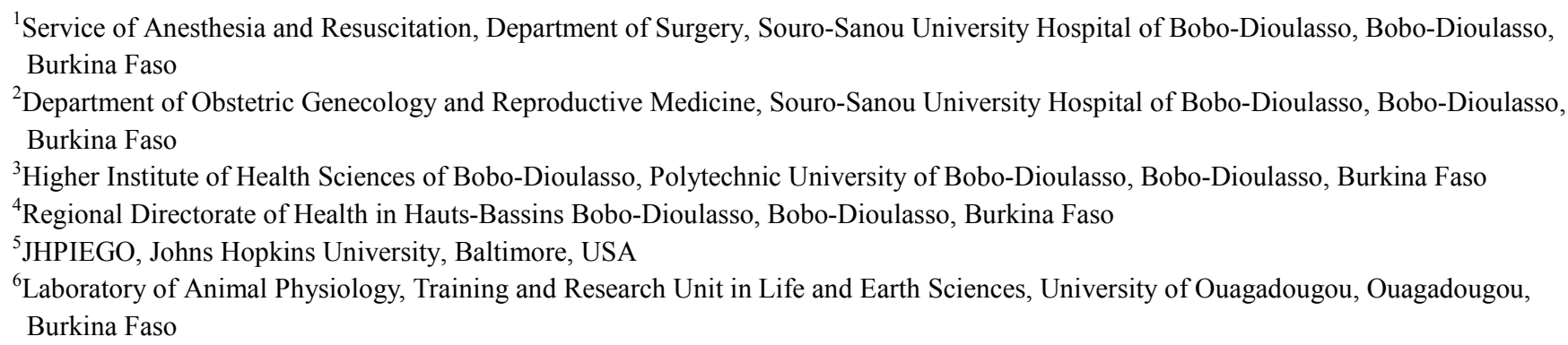

\section{Email address:}

drissab@yahoo.fr (Barro S. D.)

\section{To cite this article:}

Barro S. D., Somé D., Traoré I. A., Guibla I., Meda Z. C., Ouattara S., Dao B., Bayala B. Check Up on Anaesthesia for Caesarean Section in a Medical Center with Surgical Antenna in Bobo-Dioulasso, Burkina Faso. Journal of Diseases and Medicinal Plants.

Vol. 2, No. 1, 2016, pp. 1-4. doi: 10.11648/j.jdmp.20160201.11

\begin{abstract}
Objective: To make an inventory of anesthesia used during caesarean section in an urban medical center with surgical antenna in Bobo-Dioulasso. Patients and methods: This was a descriptive and retrospective study covering the year 2013. It concerned all women who delivered by caesarean section at Dafra, an urban district hospital. The caesarean indications were classified into extreme emergency, real/absolute emergency, delayed emergency and scheduled caesarean section. We reviewed medical records to extract data. Then analysis was performed with Excel 2000 Software. Results: A total of 291 operated women were collected, which represented $50 \%$ of the surgical activity of this hospital; $97.6 \%$ were performed in emergency. Half were extreme emergencies $(50.2 \%)$ followed by real emergencies $(34.7 \%)$ and delayed emergencies $(12.7 \%)$, scheduled caesareans sections representing 2.4\%. General anesthesia (69\%) and spinal anesthesia (31\%) were the two techniques practiced during cesareans sections in this center. According to nurses specialized in anesthesia, spinal anesthesia was less common because of the following reasons: surgeons put pressure on them, fear of hypotension during spinal anesthesia, absence of a physician anesthetist in the team, lack of training on spinal anesthesia. Conclusion: The regional anesthesia is the choice technique during all caesarean sections. It is advantageous for the mother and fetus and should be practiced even in district hospitals.
\end{abstract}

Keywords: Caesarean Section, Anesthesia, Regional Anaesthesia

\section{Introduction}

The Caesarean section is increasing worldwide [1, 2]. In Burkina Faso, this intervention has also with surgical antenna become common thanks to the opening of many Medical Centers. Caesarean section is an important part of the surgical activity in these Medical Centers. It is performed under general anesthesia (GA) or locoregional anesthesia (ALR). The choice of anesthetic technique can be done when taking into account the opposite-indications, the different techniques and their respective benefits and drawbacks and the degree of urgency of the cesarean section [3].

In Burkina Faso peripheral centers as in many developing countries, facing the lack of medical specialists, anesthesia is practiced by specialist nurses in anesthesia.

The aim of this study is to make an inventory of anesthesia for caesarean in an urban Medical Center with Surgical Antenna in Bobo-Dioulasso. 


\section{Patients and Methods}

It is a descriptive and retrospective study covered from January the 1 st to December the 31 st, 2013.

The study was carried out in the Medical Center of Dafra, a health district in Bobo-Dioulasso City. Located in the east of the city, it is one of the two urban Medical Centers with Surgical Antenna in Bobo-Dioulasso. This is the first reference level for 37 Health Centers and Social Promotion. It covers a population of 483,366 inhabitants. During the study period, this Medical Center staff consisted of 25 workers: 1 doctor gynecologist and obstetrician, a general practitioner with expertise in essential surgery, 11 specialist nurses in anesthesia and 12 nurses specialized in surgery.

The district hospital had two operating theaters and a recovery room with one bed. The interventions were practiced by a team of a doctor, two nurses specialized in anesthesia and 2 nurses specialized in surgery.

Were included in this study, all women who delivered by cesarean section at Dafra district hospital and the specialist nurses who practiced anesthesia during the period of study.

Depending on the degree of urgency, Lucas proposed a classification of caesarean sections in 4 categories: extreme urgency, true/ absolute urgency, urgency and deferred caesarean section [4]. In France, this classification was changed in color-coded "red-orange-green" [5] (Table 1).

Table 1. Lucas modified classification applied to caesarean [5].

\begin{tabular}{|c|c|c|}
\hline $\begin{array}{l}\text { Extreme emergency "Code Red": decision time / Birth } \\
<15 \mathrm{mn} \text {. Birth as soon as possible }\end{array}$ & $\begin{array}{l}\text { Caesareans "Code Orange": decision } \\
\text { time / birth < } \mathbf{3 0} \text { min. Emergency birth }\end{array}$ & $\begin{array}{l}\text { Elective caesarean "Green Code": decision } \\
\text { time / Birth }<1 \text { h. Elective birth }\end{array}$ \\
\hline $\begin{array}{l}\text { - Fetal bradycardia (without recovery of RCF in } 10 \mathrm{mn} \text { ) } \\
\text { - Failed instrumental delivery on ARCF being expelled } \\
\text { - Suspicion DPPNI (retro placental hematoma) } \\
\text { - Placenta previa with abundant maternal hemorrhage } \\
\text { - Suspicion of uterine rupture } \\
\text { - Prolapsed cord }\end{array}$ & $\begin{array}{l}\text { - FHR abnormalities (outside } \\
\text { bradycardia) } \\
\text { - } \begin{array}{l}\text { Failed instrumental extraction } \\
\text { without ARCF }\end{array}\end{array}$ & $\begin{array}{l}\text { - Trigger Failed } \\
\text { - Stagnation of the expansion or the descen } \\
\text { of the presentation } \\
\text { - Patient in spontaneous labor and having an } \\
\text { elective scheduled }\end{array}$ \\
\hline
\end{tabular}

Data were collected through a predetermined survey sheet. They concerned the indications for caesarean section, anesthetic technique, drugs and materials used the encountered difficulties. The main sources were gathering medical records, the register of operating protocols, monitoring anesthetic sheets and the birthing register. Data analysis was made by Excel 2000 Software.

\section{Results}

During the study period, 291 caesarean sections were performed, which represented $50 \%$ of all surgical activities of the Medical Center.

\subsection{Emergency Caesareans}

A total of 284 cases caesarean sections (97.6\%) were performed in emergency in ration to $2.4 \%$ of scheduled caesarean sections ( 7 cases). Direct admissions were 228 cases $(78.4 \%)$ and references 63 cases $(21.6 \%)$ from Health Centers and Social Promotion.

\subsection{Degree of Emergency and Type of Anesthesia}

The distribution of caesarean sections depending on the type of anesthesia practiced and the degree of urgency is shown in Table 2.

Table 2. Distribution of caesarean sections by type of anesthesia and the degree emergency.

\begin{tabular}{|c|c|c|c|}
\hline Degree of emergency & Type anesthesia & & Total (\%) \\
\hline & General anesthesia (\%) & Spinal (\%) & \\
\hline Extreme emergency & $122(83.6)$ & $24(16.4)$ & $146(50.2)$ \\
\hline True emergency & $64(63.4)$ & $37(36.6)$ & $101(34.7)$ \\
\hline Delayed emergency & $10(27.0)$ & $27(73.0)$ & $37(12.7)$ \\
\hline Scheduled & $5(61.4)$ & $2(28.6)$ & $7(2,4)$ \\
\hline Total & $201(69.0)$ & $90(31.0)$ & $291(100)$ \\
\hline
\end{tabular}

\subsection{Materials and Drugs Used for Anesthesia (Spinal and GA)}

The main materials and drugs used during anesthesia (GA or ALR) were as follows: intubation probes (7 or 6.5), hypnotics (propofol, ketamine, pentothal), muscle relaxants (suxamethonium), opioids (fentanyl, sufentanyl), local anesthetics (2\% lignocaine, bupivacaine $0.5 \%)$, crystalloid (normal saline, ringer lactate), vasopressors (ephedrine 3\%), lumbar puncture needle 22G. Surveillance was made with multiparameter monitors.

\subsection{Difficulties Related to the Practice of Spinal Anesthesia}

The main reasons for not performing anesthesia given by the nurses specialized in anesthesia during caesarean sections have been: the pressure of surgeons, fear of hypotension following spinal anesthesia, the absence of an physician anesthetist, lack of training / retraining on technique and the fear of failure of lumbar puncture.

\section{Discussion}

The anesthesia for caesarean section is a common event in 
obstetrics $[1,6,7]$. Indeed, despite ongoing efforts, this mode of delivery has remained stable or even an increasing [1, 7]. As shown in our results, cesarean section is in most cases done in a context of obstetric emergency [3]. The classification of caesareans sections according to the degree of urgency, has established a decision-extraction period (DEP) of the child, for each category [4, 5, 8]. Two anesthetic techniques (GA or ALR) are conventionally used and the choice of one is guided by the degree of emergency. The anesthetist for cesarean knowed a significant change. Indeed GA widely practiced in the 70 s $(70-80 \%)$, currently accounts for only $5-10 \%$ of anesthesia for caesarean section [9]. The morbidity and mortality associated with caesarean occurs in most cases in the GA $[10,11]$. Today cesareans sections under GA have become rare and they concern the extreme urgency and absolute opposite-indications of the ALR $[6,12]$. We admit, despite recent disputes that the time between the decision to cesarean and the birth of the fetus must not exceed 30 minutes in the conditions of real urgency [8]. The recommendations for good clinical practice advocate ALR perimedullaire (spinal, epidural, combined spinalepidural) for caesarean section if conditions are met $[8,13$, 14]. ALR offers many benefits for both mother and child [15]. When peridural catheter was placed for analgesia in the delivery room, it is recommended to extend the epidural for caesarean section $[6,14]$. The success of this expansion technique is conditioned by the running of analgesia for the duration of delivery $[16,17,18]$. The choice of spinal anesthesia technique occurred in case of extreme emergency and absence of epidural catheter. This technique has many advantages such the ease of implementation, the installation speed and quality of anesthesia it provides. The main disadvantages are headache (prevented by the use of needletip pen and 25-27 diameters G) and induced hypotension (corrected by vasopressors and filling) [19]. As for the combined peri-spinal, it is especially indicated in the case of elective caesarean section. His place in the context of the emergency seems marginal, due to the period of its implementation [3].

Regardless of the anesthetic technique used, the presence of qualified and competent personnel (physician anesthesiologist, nurse anesthetist) is an important factor in the quality and safety of anesthesia resuscitation care in obstetrics [3,6]. Also communication between obstetricians and anesthesia team is important to discuss the degree of urgency, in order to adapt to the situation anesthetic technique $[3,20]$.

\section{Conclusion}

Anesthesia for Cesarean section today is performed mostly by regional anesthesia, even if the cesarean section is urgent. In case of general anesthesia, increasingly rare, it must consider the risk of difficult intubation and inhalation first, and also anticipate the management of post-operative pain by analgesia multimodal.

\section{References}

[1] JG Jenkins, MM Khan. Anaesthesia for caesarean section: a survey in UK Region from 1992 to 2002. Anaesthesian. 2003; 58: 1114-18.

[2] SM Yentis. Distress Whose is it anyway? Fetal distress and the 30 minutes rule. Anaethesia. 2003; 58: 732-3.

[3] CC Arvieux, B Rossignol, G Gueret, M Havaux. Anesthesia for emergency caesarean section. In: Sfar, ed. Conferences discount. National congress of anesthesia and resuscitation. Paris: Elsevier; 2001; p. 9-25.

[4] DN Lucas, SM Yentis, SM Kinsella, A Holdcroft, AE May, M Wee, et al. Urgency of caesarean section: a new classification. JR Soc Med. 2000; 93: 346-50.

[5] O Dupuis, I Sayegh, E Decullier, C Dupont, HJ Clément, M Berland, RC Rudigoz. Red, orange and green caesarean sections: A new communication tool for on-call obstetricians. Eur J Obstet Gynecol Reprod Biol. 2008; 140: 206-11.

[6] N TheNoz, S Soler, E Boselli, D Chassard. Anesthesia for caesarean section Eds Elsevier. 2005; p. 323-33.

[7] J Villar, E Valladares, D Wojdyla, N Zavaleta, G Carroli, A Velazco, A Shah, Caesarean delivery rates and pregnancy outcomes: The 2005 WHO global survey is maternal and perinatal health in Latin America Lancet. 2006; 367: 1819-29.

[8] NICE Clinical Guidelines. Caesarean Section. November 2011. Published by the Royal College of Obstetricians and Gynaecologists, 27 Sussex Place, Regent's. Park, London NW1 4RG. Website: www.rcog.org.uk.

[9] RV Johns, GR Lyons, RC Wilson, AP Robinson. Training in obstetric general anesthesia: a vanishing art? Anaesthesia. 2000; 55: 179-83.

[10] C Deneux-Tharaux, E Carmona, MH Bouvier-Colle. Postpartum maternal mortality and caesarean delivery. Obstet Gynecol. 2006; 108: 541-48.

[11] JL1 Hawkins, J Chang, SK Palmer, CP Gibbs, WM Callaghan. Anesthesia-related maternal mortality in the United States: 1979-2002. Obstet Gynecol. 2011; 117: 69-74.

[12] AGM Aya, N Vialles, J Ripart. Anesthesia and eclampsia Ann Fr Anesth Reanim 2010; 29: 141-47.

[13] P Popham, A Buettner, $M$ Mendola. Anaesthesia for emergency caesarean section 2000-2004, at the Royal Women's Hospital, Melbourne Anaesth Intensive Care. 2007; 35: 74-79.

[14] KJ Regan, G O'Sullivan. The extension of epidural blockade for emergency caesarean section: a survey of current UK practice. Anaesthesia. 2008; 63: 136-142.

[15] W Krisanaprakornkit, Anesthesia spinal or epidural in case of caesarean section: BSG commentary (last revision 15 December 2006). Library that of WHO reproductive health; Genève: World Health Organization.

[16] ME Bauer, JA Kountanis, LC Tsen, ML Greenfield, JM Mhyre. Risk factoring for failed labor epidural analgesia conversion of cesarean delivery to anesthesia: a systematic review and meta- analysis of observational trials. Int J Obstet Anesth. 2012; 21: 294-309. 
[17] E Depuydt M Van De Velde. Unplanned cesarean section in parturients with an epidural catheter in-situ: how to obtain surgical anesthesia. Acta Anaesth Belg. 2013; 64: 61-74.

[18] SH Halpern, A Soliman, J Yee, P Angle, A Ioscovich. Conversion of epidural anesthesia for labor analgesia to Caesarean section: a prospective study of the incidence and determinants of failure. Br J Anaesth. 2009; 102: 240-3.
[19] B Carvalho, FJ Mercier, ET Riley, C Brummel, SE Cohen. Hetastarch co-loading is as effective as pre-loading for the prevention of spinal anesthesia for hypotension following cesarean delivery. Intern J Obstet Anesth. 2009; 18: 150-5.

[20] A George. A response to Whose distress is it anyway? Fetal distress and the 30-min rule. Anaesthesia. 2004; 59202. 